SHORT REPORT

\title{
Central nervous system Aspergillus fumigatus infection after near drowning
}

P A Kowacs, S Monteiro de Almeida, R L Pinheiro, H Fameli, E J Piovesan, A Correia, L C Werneck

J Clin Pathol 2004;57:202-204

Aims: To report the case of a 26 year old white man, who developed chronic meningitis and intracerebral granulomata 15 days after an episode of near drowning in a swamp. Methods: Aspergillus fumigatus was isolated from cerebrospinal fluid cultures.

Results: The patient died 70 days after the symptoms were first noticed, and seven days after a subarachnoid haemorrhage. Aspergillus has never been reported before as a cause of intracranial infection after near drowning. Conclusions: Physicians must be aware of this possibility when confronted with such a situation, because there are now effective therapeutic options for systemic aspergillosis.

A spergilli are probably the most common group of fungi in our environment. Most aspergillus species are found in the soil. Aspergillosis occurs worldwide, with no apparent age, sex, or race differentials. The major pathogen, Aspergillus fumigatus, is found in the soil, but is seen most abundantly in decomposing organic materials. ${ }^{1}$ Aspergillus hyphae can be seen in clinical specimens using direct microscopic examination, and show dichotomous branching of septate hyaline hyphae with a typical acute angle. Aspergillus spp grow well on a variety of conventional agar media, produce spore chains, conidiophores, and conidial heads (L Renon. Recherches cliniques et experimentales sur la pseudotuberculose aspergillare. Thesis. Paris: 1893: No. 89). Invasive aspergillosis is a severe infection that leads to death in $90 \%$ of cases if not recognised early. ${ }^{2}$ Involvement of the central nervous system (CNS) in aspergillosis adds a further mortality risk. ${ }^{3}$ Although invasive aspergillosis usually occurs in immune depressed individuals, such as those suffering from major burns, AIDS, and immune disorders, in addition to transplant recipients, it may eventually cause disease in healthy individuals. ${ }^{4}$ The unique case of a young man who developed CNS aspergillosis after near drowning is reported.

"Invasive aspergillosis is a severe infection that leads to death in $90 \%$ of cases if not recognised early"

\section{CASE REPORT}

A 26 year old white man suffered near drowning in a mangrove swamp on the seacoast of São Paulo, in eastern Brazil. After being taken to a nearby hospital, he was treated for aspirating pneumonia and was released after two days. Two weeks later he started complaining of headache of progressive intensity, and after 14 days he was submitted to a computerised tomography (CAT) scan and to magnetic resonance imaging (MRI) of the head, which revealed several hypodense lesions suggestive of granulomata. He was then referred and admitted to our clinic. On admission, he was still complaining of headaches, but his physical and neurological examinations were unremarkable, except for the presence of a mild fever $\left(37.2^{\circ} \mathrm{C}\right)$ and mild meningismus. His red blood cell count was normal $\left(4.85 \times 10^{12}\right.$ /itre; haemoglobin, $132 \mathrm{~g} /$ litre) but there was pronounced neutrophilic leucocytosis $\left(20000 \times 10^{6}\right.$ cells/litre; $84 \%$ neutrophils $(80 \%$ segmented, $4 \%$ bands), $10 \%$ lymphocytes, and $6 \%$ monocytes). His erythrocyte sedimentation rate was $27 \mathrm{~mm} / \mathrm{h}$, blood glucose and creatinine were normal. An $x$ ray of the lungs disclosed interstitial micronodular lesions. An electrocardiogram showed no abnormalities. Cerebrospinal fluid (CSF) examination revealed neutrophilic meningitis $\left(165 \times 10^{6}\right.$ cells/ litre; $69 \%$ neutrophils, $31 \%$ lymphocytes), with a normal glucose $(3.55 \mathrm{mmol} /$ litre) but high total proteins $(0.778 \mathrm{~g} /$ litre). Pseudallescheriasis was suspected, and broad spectrum antibiotics, in addition to antifungal treatment were started, with $1 \mathrm{~g}$ ceftriaxone given intravenously (IV) twice a day (b.i.d.), $500 \mathrm{mg}$ metronidazole IV b.i.d., $2 \mathrm{ml}$ cotrimoxazole IV four times a day (q.i.d.), $200 \mathrm{mg}$ fluconazole IV b.i.d., $4 \mathrm{mg}$ dexamethasone IV three times a day (t.i.d.), and $100 \mathrm{mg}$ ketoprofen IV b.i.d. A stereotactic biopsy was planned but cancelled because a CAT scan performed five days later showed amelioration of the brain lesions. At this time, his blood count was normal, but the leucocytosis had increased $\left(28500 \times 10^{6}\right.$ cells/litre; 91\% neutrophils $(83 \%$ segmented, $8 \%$ bands), $6 \%$ lymphocytes, and 3\% monocytes). In addition, transaminases were slightly increased (aspartate aminotransferase (AST), $2.32 \mathrm{ukat} / \mathrm{litre}$, alanine aminotransferase (ALT), 2.08 ukat/litre). After 10 days of treatment, the low grade fever and headache recurred. The number of neutrophils in the peripheral blood had increased (32 $400 \times 10^{6}$ cells/litre; $82 \%$ neutrophils-76\% segmented, $6 \%$ bands, $10 \%$ lymphocytes, and $8 \%$ monocytes), and CSF examination showed $280 \times 10^{6}$ cells/litre, mostly $(64 \%)$ neutrophils, an increased total protein $(0.89 \mathrm{~g} /$ litre $)$, and a normal glucose (3.05 mmol/litre). Serum AST had returned to normal values but ALT remained somewhat high ( 1.73 ukat/litre). Serum anti-human immunodeficiency virus enzyme linked immunosorbent assay of blood was negative. Blood cultures and a search for fungi in CSF stains and cultures yielded negative results. After 12 days of treatment the patient became confused and disoriented. Although his CSF findings had slightly improved, $150 \mathrm{mg}$ itraconazole IV b.i.d., together with $30 \mathrm{mg}$ /day amphotericin B IV, was given instead of fluconazole. There was a partial response to treatment, but after two days $300 \mathrm{mg} /$ day IV pentamidine was added to the treatment regimen because an amoebic infection was suspected. The dose of amphotericin B was

\footnotetext{
Abbreviations: Abbreviation: ALT, alanine aminotransferase; AST, aspartate aminotransferase; CAT, computerised tomography; CNS, central nervous system; CSF, cerebrospinal fluid; IV, intravenous; b.i.d., twice a day; t.i.d., three times a day; q.i.d., four times a day; MRI, magnetic resonance imaging
} 
increased to $70 \mathrm{mg} /$ day and given with $0.5 \mathrm{mg}$ amphotericin B intrathecally every other day. Haloperidol $(5 \mathrm{mg}$ ) was given at bedtime for night agitation. His condition continued to deteriorate over the following days. A few small papullar skin lesions ensued, and he suddenly presented a pronounced meningismus, associated with a left conjugate gaze palsy and a left sided weakness, involving mainly his left arm. CSF examination showed a haemorrhage superimposed on the meningitis, and his CAT scan disclosed blood in the subarachnoid spaces, enlarged ventricles, and an almost complete resolution of the granulomata. CSF findings revealed an increase in the number of leucocytes $\left(148.8 \times 10^{6}\right.$ cells/litre; 93\% neutrophils), an increase in CSF protein $(0.29 \mathrm{~g} /$ litre $)$, and a decrease in CSF glucose ( $1.16 \mathrm{mmol} /$ litre). His blood creatinine had risen to $1768 \mu \mathrm{mol} /$ litre. He was transferred to the intensive care unit. At this time, A fumigatus was isolated from the CSF culture. Ceftriaxone, pentamidine, and cotrimoxazole were discontinued and $3 \mathrm{~g}$ ceforoxime IV t.i.d., $600 \mathrm{mg}$ clindamicin IV q.i.d., and $500 \mathrm{mg} /$ day methylprednisolone were added to metronidazole and itraconazole. However, the patient's condition continued to deteriorate and he died 56 days after being admitted for treatment.

\section{DISCUSSION}

CNS aspergillosis is a rare condition in immunocompetent hosts, and is favoured by working in agriculture, craftwork, and by a tropical climate. ${ }^{5}$ In patients with few risk factors, the entire disease period can last from 9.5 months to four years. ${ }^{5}$ Diabetes mellitus type II seems to be a predisposing condition. ${ }^{56}$ Primary sites of infection are the lungs in the immunodepressed, ${ }^{6}$ and the paranasal sinus in immunocompetent individuals. ${ }^{5-7}$ Less frequently, gastrointestinal and skin infection preceding CNS infection can occur, and more rarely CNS primary infection without an extracranial source. $^{5}{ }^{6}$ Immunocompetent patients may present with multiple cranial nerve disorders, a cavernous sinus syndrome, or with an orbital apex syndrome, reflecting local invasion from paranasal sinuses. ${ }^{5}$ Isolated or multiple granulomata may also occur and present focal signs, associated or not associated with meningitis. ${ }^{5}$ These presentations differ from that seen in the immunodepressed, in whom there are multiple areas of brain infarction, haemorrhage, encephalomalacia, and isolated or multiple abscesses, leading to infectious and/or stroke syndromes. ${ }^{6}$ CSF smears should be carefully examined with India ink for fungi, but will rarely be positive. $^{8}$ In our patient, special care was taken to avoid confusion with Pseudallescheria boydii, a fungus that may invade the CNS after near drowning, and that may resemble an aspergillus infection. ${ }^{910}$ Another important differential diagnosis is CNS infection by free living amoebae, such as Acanthamoeba spp, and particularly Naegleria spp, which is related to swimming in, or contact with, polluted waters or lakes. ${ }^{11} 12$

\footnotetext{
"Although intravenous amphotericin B has been the mainstay treatment for CNS aspergillosis, two new drugs for intravenous use-voriconazole and caspofungin - are promising agents, with a good tolerability profile"
}

Because Aspergillus spp are difficult to detect in CSF smears and cultures, the determination of serum aspergillus galactomannan, with two positive results, coupled with typical radiological findings, is highly sensitive and specific to support the diagnosis. ${ }^{13}$ In immunodepressed individuals, typical MRI and CAT scan findings in the paranasal sinus and lungs, respectively, may suggest the diagnosis. The CSF determination of galactomannan is
Take home messages

- We report the case of a 26 year old white man, who developed chronic meningitis and intracerebral granulomata after near drowning in a swamp

- Aspergillus fumigatus was eventually isolated from cerebrospinal fluid cultures, but he died 70 days after the symptoms were first noticed, and seven days after a subarachnoid haemorrhage

- Aspergillus spp have never been reported before as a cause of intracranial infection after near drowning and physicians should be aware of this possibility because there are now effective therapeutic options for systemic aspergillosis

also a promising diagnostic tool. ${ }^{13}$ A case in which the diagnosis was clarified through MRI findings and CSF polymerase chain reaction to Aspergillus spp has been reported. ${ }^{14}$

Treatment for invasive aspergillosis has changed since our case was studied. Amphotericin B and other clinical and surgical alternatives showed few encouraging results. ${ }^{15-17}$ Although intravenous amphotericin B has been the mainstay treatment for CNS aspergillosis, two new drugs for IV usevoriconazole and caspofungin—are promising agents, with a good tolerability profile. ${ }^{18-22}$

Pseudallescheria boydii CNS infections have been described after near drowning in dirty and polluted waters or in manure reservoirs. Amoebic CNS infections are reported to occur after swimming in dirty pools or reservoirs. However, before our case, Aspergillus spp had not been suspected as a possible aetiology after near drowning. Because infection with aspergillus can be diagnosed and treated, it should always be considered when involvement of the CNS begins after an episode of near drowning.

\section{ACKNOWLEDGEMENTS}

The authors thank Janssen-Cilag for the donation of intravenous itraconazole for treating this patient. Dr Fameli was supported by PIBIC/CNPq.

\section{Authors' affiliations \\ P A Kowacs, S Monteiro de Almeida, H Fameli, E J Piovesan,}

L C Werneck, Neurology Division, Internal Medicine Department, Hospital de Clínicas da Universidade Federal do Paraná, 80060-900, Curitiba, Brazil

A Correia, Neurosurgery Department, Hospital de Clínicas da Universidade Federal do Paraná

S Monteiro de Almeida, R L Pinheiro, Clinical Analysis Laboratory, Hospital de Clínicas da Universidade Federal do Paraná

Correspondence to: Dr P A Kowacs, Neurology Division, Internal Medicine Department, Hospital de Clínicas da Universidade Federal do Paraná, Rua General Carneiro 181, Sala 1236, 80060-900, Curitiba, Brazil; cefaleia@hc.ufpr.br

Accepted for publication 17 July 2003

\section{REFERENCES}

1 Kwon Chung KJ, Bennett JE. Aspergillosis. In: Kwon Chung KJ, Bennett JE, eds. Medical mycology. Philadelphia: Lea \& Febiger, 1992:201-47.

2 von Eiff $M$, Zuhisdorf $M$, Roos $N$, et al. Pulmonary fungal infections in patients with hematological malignancies-diagnostic approaches. Ann Hematol 1995;70: 135-41

3 Hedges TR. Parasellar and orbital apex syndrome caused by aspergillosis. Neurology 1976;26:117-20. 
4 Verwei J PE, Denning DW. The challenge of invasive aspergillosis: increasing numbers in diverse patient groups. Int $J$ Infect Dis 1997;2:61-3.

5 Murphy JMK, Sundarmc Prasad VSSV, Purohit AK, et al. Aspergillosis of central nervous system: a study of 21 patients seen in a university hospital in South India. J Assoc Physicians India 2000;48:677-81.

6 Torre-Cisneros J, Lopez OL, Kusne S, et al. Aspergillosis in organ transplantation: a clinicopathological study. J Neurol Neurosurg Psychiatry 1993;56:188-93.

7 Yanai Y, Wakao T, Fukamachi A, et al. Intracranial granuloma caused by Aspergillus fumigatus. Surg Neurol 1985;23:597-604.

8 Palo J, Haltia M, Uutela T. Cerebral aspergillosis with special reference to cerebrospinal fluid findings. Eur Neurol 1975;13:224-31.

9 Kershaw P, Freeman R, Templeton D, et al. Pseudallescheria boydii infection of the central nervous system. Arch Neurol 1990;47:468-72.

10 Rüchel R, Wilichowski E. Cerebral Pseudallescheria mycosis after neardrowning. Mycoses 1995;38:473-5.

11 Martinez AJ. Infection of the central nervous system due to Acanthamoeba. Rev Infect Dis 1991;13(suppl 5):399-402.

12 Martinez AJ. Free-living amebas: infection of the central nervous system. Mont Sinai J Med 1993;60:271-8.

13 Denning DW. Early diagnosis of invasive aspergillosis. Lancet 2000;5:423-4.

14 Kami M, Shirouzu I, Mitani K, et al. Early diagnosis of central nervous system aspergillosis with combination use of cerebral diffusion-weighted echo-planar magnetic resonance image and polymerase chain reaction of cerebrospinal magnetic resonance image and
fluid. Int Med 1999;38:45-8.
15 Coleman JM, Hogg GG, Rosenfeld JV, et al. Invasive central nervous system aspergillosis: cure with liposomal amphotericin B, itraconazole, and radical surgery-case report and review of the literature. Neurosurgery 1995:36:858-63.

16 Imai T, Yamamoto T, Tanaka S, et al. Successful treatment of cerebral aspergillosis with a high oral dose of itraconazole after excisional surgery. Intern Med 1999;38:829-32.

17 Touza RF, Martinez VC, Alonso AJ, et al. The clinical response to interferongamma in a patient with chronic granulomatous disease and brain abscesses due to Aspergillus fumigatus. Ann Med Interne (Paris) 2000;17:86-7.

18 Schwartz S, Milatovic D, Thiel E. Successful treatment of cerebral aspergillosis with a novel triazole (voriconazole) in a patient with acute leukaemia. Br J Haematol 1997;97:663-5.

19 Abruzzo GK, Gill CJ, Flattery AM, et al. Efficacy of the echinocandin caspofungin against disseminated aspergillosis and candidiasis in cyclophosphamide-induced immunosuppressed mice. Antimicrob Agents Chemother 2000;44:2310-18.

20 Keating GM, Jarvis B. Caspofungin. Drugs 2001;61:1121-9.

21 Arikan S, Lozano-Chiu M, Paetznick V, et al. In vitro synergy of caspofungin and amphotericin B against Aspergillus and Fusarium spp. Antimicrob Agents Chemother 2002;46:245-7.

22 Walsh TJ, Pappas P, Winston DJ, et al. Voriconazole compared with liposomal amphotericin $B$ for empirical antifungal therapy in patients with neutropenia and persistent fever. New Engl J Med 2002;346:225-34. 